Zbornik Instituta za kriminološka

i sociološka istraživanja

2021 / Vol. XL / 2-3 / 9-20

Originalni naučni rad

Primljeno: 1. 12. 2021. godine

Prihvaćeno: 16. 12. 2021. godine

DOI: $10.47152 /$ ziksi20212301

UDK: 005.963.1

\title{
EVALUACIJA EFEKTIVNOSTI GRUPNIH I INDIVIDUALNIH OBUKA U ORGANIZACIJI U CILJU UNAPREĐIVANJA KOMPETENCIJA ZAPOSLENIH ${ }^{*}$
}

\author{
Hajdana Glomazić ${ }^{*}$
}

\begin{abstract}
Predmet rada je evaluacija efektivnosti grupnih $i$ individualnih obuka u organizaciji. Cilj rada je pružanje odgovora na pitanje da li su sprovedene grupne $i$ individualne obuke bile efektivne u smislu unapređivanja kompetencija zaposlenih. Korišćena metoda je strukturirani intervju. Rezultati su pokazali da su ispitanici procenili da su i grupne $i$ individualne obuke bile visoko efektivne kako na ličnom, tako i na profesionalnom planu. Međutim, verujemo da je tako visoko ocenjena efektivnost obuka više proizvod sinergïje celokupnog rada organizacije na organizacionim promenama $i$ preduzetih obrazovnih intervencija, nego isključivo same obrazovne aktivnosti.
\end{abstract}

KLJUČNE REČI: organizacija / kompetencije / obuke / efektivnost obuka / ljudski resursi

\section{UVOD}

Brojni autori naglašavaju da društva zasnovana na znanju i preduzetništvu postaju pokretači ekonomskog razvoja i inovacija, čime doprinose smanjenju nezaposlenosti, otvaranju mogućnosti uspešne integracije mladih i već zaposlenih $u$

\footnotetext{
* Ovaj rad nastao je kao rezultat istraživačkog angažovanja prema Planu i programu rada Instituta za kriminološka i sociološka istraživanja za 2021. godinu.

* Naučni saradnik u Institutu za kriminološka i sociološka istraživanja. E-mail: hajdana.ng@gmail.com
} 


\author{
Zbornik IKSI, 2-3/2021 - H. Glomazić \\ „Evaluacija efektivnosti grupnih i individualnih obuka u organizaciji u cilju unapređivanja \\ kompetencija zaposlenih", (str. 9-20)
}

globalni sistem rada, koji se pod uticajem aktuelnih trendova ubrzano menja (Glomazić, Ljumović \& Jakšić, 2020). U tom smislu, organizacije treba da pokažu zainteresovanost da se uključe u savremene ekonomske tokove kako bi u izmenjenim društvenim okolnostima ostale konkurentne. Usled toga, autori smatraju da je potrebno pažljivo upravljati ljudskim resursima, organizacionim učenjem i razvojem, jer orijentacija na inovativnost i razvoj zaposlenih može biti snažan mehanizam njihovog daljeg razvoja i unapređivanja kompetencija, a samim tim i povećanja organizacione produktivnosti (Slavković \& Slavković, 2019; Stanišić Vještica, 2016).

Unapređivanje kompetencija u organizaciji često se realizuje putem neformalih oblika obrazovanja u koje se ubrajaju obuke. Autori navode da korišcenje kompetencija zaposlenih u najvećoj meri zavise od obrazovanja i obuke i da ova funkcija ima najveći značaj u upravljanju ljudskim resursima (Stanišić Vještica, 2016).

U ovom radu pod pojmom obuka podrazumevamo sistematski proces koji pokreće organizacija, a koji omogućava relativno trajne promene kompetencija koje se odražavaju na promene u znanju, veštinama ili stavovima članova organizacije (Kraiger, 2017), dok se pod kompetencijama podrazumeva „integrisani skup znanja, veština, sposobnosti i stavova koji omogućavaju pojedincu efikasno obavljanje aktivnosti u poslu, u skladu sa očekivanim standardom“ (Nacionalni okvir kvalifikacija, 2017).

Pod efektivnošću obuka podrazumevamo ishode učenja, odnosno promene koje su se dogodile u procesu učenja kao što su: efekti učenja, stečene veštine, povećana znanja, usvojeni pozitivni stavovi, promene u ponašanju. Takođe, efektivnost može da podrazumeva i mogućnost zaposlenih da se promovišu u bolju poziciju, odnosno da se poboljšaju performanse organizacije ili njena pozicija na tržištu (Mihailova et al., 2018).

Predmet rada je evaluacija efektivnosti grupnih i individualnih obuka kao obrazovnih intervencija sprovedenih u organizaciji. Cilj rada je pružanje odgovora na pitanje da li su sprovedene grupne i individualne obuke bile efektivne u smislu unapređivanja kompetencija. Korišćena metoda je strukturirani intervju.

\title{
1. OBUKE KAO FAKTOR UNAPREĐIVANJA KOMPETENCIJA
}

U svetu rada koje je određen brojnim izazovima, kao što su pomeranja na tržištu rada, mobilnost radne snage, sveprisutno uvođenje IT tehnologija u radu, nedostatak kvalifikovanih radnika, rad na daljinu uslovljen posledicama pandemije COVID-19 - doživotno učenje i obrazovanje postalo je imperativ. Doživotno učenje i kontinuirano unapređivanje kompetencija je osnovni instrument razvoja ljudskih resursa: ono je uslov ekonomskog uspeha uopšte i ličnog uspeha pojedinca (European Commission, 2007). Evropski parlament i Veće su 2006. godine doneli Preporuku o ključnim kompetencijama za doživotno učenje (European Union, 2006). Tako je „Evropskim referentnim okvirom ključnih kompetencija“ za 


\author{
Zbornik IKSI, 2-3/2021 - H. Glomazić \\ „Evaluacija efektivnosti grupnih i individualnih obuka u organizaciji u cilju unapređivanja \\ kompetencija zaposlenih", (str. 9-20)
}

doživotno učenje definisano 8 ključnih kompetencija koje svakom pojedincu obezbeđuju ličnu ostvarenost i razvoj, društvenu uključenost, aktivnu građansku ulogu i zaposlenost. Kako se kaže u dokumentu, one se sastoje od znanja, veština i stavova i nadilaze pojam samog (akademskog) znanja (European Union, 2006).

Istovremeno istraživači naglašavaju da se programima obuke mogu razvijati različite kompetencije, jer obuke omogućavaju sistemski pristup učenju u cilju poboljšanja individualne, timske i organizacione efektivnosti (Goldstein \& Ford, 2002). Povezanost između obuka, razvijanja kompetencija, povećanja radnog učinka, smanjene fluktuacije i zadovoljstva poslom, pokazana je u različitim studijama (Chih, Lee \& Liu, 2008; Acton \& Golden, 2003). Domaćim zakonskim propisima, unapređivanje kompetencija, stručno osposobljavanje zaposlenih, obrazovanje i obuka regulisani su čak i kao obaveza poslodavaca, ukoliko to zahtevaju potrebe procesa rada i uvođenje novog načina organizacije rada (Zakon o radu, 2018). Tako se Uredbom o određivanju kompetencija za rad državnih službenika (Službeni glasnik RS, 4/2019) pristupilo definisanju funkcionalnih opštih i posebnih i (još uže) ponašajnih kompetencija.

Da bi obuke bile efektivne u smislu unapređenja kompetencija zaposlenih, moraju se zadovoljiti određeni preduslovi. Pre svega, oni se odnose na dobro osmišljen kurikulum (Kraiger, 2017). Obuka na poslu ne predstavlja samo direktno sticanje znanja koje zaposlenom pomaže da razvije i uveća kompetencije, već predstavlja ponašanje i zajedničke vrednosti, što se naziva prećutna, tacitna obuka (Stanišić Vještica, 2016). „Rezultat je da ovakva tehnika osim što osobu čini pripremljenijom da obavlja svoje zadatke, omogućava prenošenje i održavanje kolektivnog znanja organizacije, koje se ne sastoji samo od poznavanja, već od zajedničkih vrednosti i smernica koje dele svi njeni članovi i tako podstiču organizacionu integraciju i stabilnost“" (Stanišić Vještica, 2016: 35).

Iako autori smatraju da se kroz obuke mogu razvijati kompetencije u punom značenju tog termina, ipak dodaju da one imaju ograničen obrazovni domet ukoliko nemaju kontinuiran karakter ili ukoliko su one jedini faktor njihovog razvoja (Pejatović i Pekeč, 2011). I drugi autori navode da iako je obuka ključna funkcija razvoja zaposlenih, može dati rezultate samo u sinergiji sa drugim razvojnim funkcijama menadžmenta (Stanišić Vještica, 2016).

$\mathrm{S}$ tim u vezi, jedno od pitanja koje se nameće je merenja učinka, odnosno efektivnosti samih obuka, kao i načina i forme njihovog dizajniranja. To je veoma kompleksan proces, usled čega autori naglašavaju da nije celishodno meriti efektivnost obuka samo na kraju seminara, jer je potrebno vreme za usvajanje znanja i veština i njihovu kristalizaciju koja će se pokazati u primeni stečenog kroz proceduralna znanja i ponašanja na radnom mestu (Mihailova et al., 2018).

\title{
2. METOD
}

Metoda korišćena u radu je strukturirani individualni intervju. Za procenu efektivnosti obuka, zaposlenima su ponuđene tri opcije za odgovor: „efektivne su“, 


\author{
Zbornik IKSI, 2-3/2021 - H. Glomazić \\ „Evaluacija efektivnosti grupnih i individualnih obuka u organizaciji u cilju unapređivanja \\ kompetencija zaposlenih", (str. 9-20)
}

„delimično su efektivne“ i „nisu efektivne“. Takođe, data im je mogućnost da obrazlože u kojim poljima su obuke bile efektivne, na profesionalnom i/ili individualnom i šta im je u najvećoj meri pomoglo u osnaživanju kompetencija.

Uzorak $\mathrm{u}$ istraživanju su predstavljali svi zaposleni u organizaciji koji rade u okviru jedinstvenog poslovnog kompleksa, na svim vrstama ugovora: neodređeno, određeno i privremeni i povremeni poslovi, kada su u pitanju grupne obuke. Planom je predviđeno da grupnim obukama prisustvuju svi zaposleni u organizaciji, dok su na individualne obuke i savetovanja mogli da se uključe oni zaposleni koji su iskazali potrebu za ovom vrstom obrazovne aktivnosti.

Grupne obuke su podrazumevale upoznavanje sa temama koje se odnose na podizanje komunikativnih kompetencija, rašavanje konflikata, timskog rada, organizacione kulture. Individualne obuke ili savetovanja su se odnosile na sve prethodne teme, sa naglaskom na osnaživanje menadžerskih kompetencija, poboljšanje poslovnih performansi, kompetencija za rešavanje poslovnih zadataka i prevazilaženje situacija koje dovode do stresa, gubljenja motivacije za rad i zadovoljstva poslom.

Grupne obuke su bile sprovedene u privrednom društvu „Dipos“ od novembra 2019. do februara 2020. godine ${ }^{1}$ kao kratkoročni tip obuka, dok se individualne obuke sprovode u istoj organizaciji svakog meseca, počevši od jula 2020. do kraja decembra 2021. godine. Istraživanje o efektivnosti je sprovedeno u periodu od 29.10.2021. do 22.11.2021. godine.

Model evaluacije koji je korišćen u radu je procena samih učesnika o efektivnosti obuka u direktnom razgovoru sa istraživačem (strukturirani intervju). Pod evaluacijom grupnih i individualnih obuka u ovom radu podrazumevamo ličnu procenu ispitanika o ishodima koje su obuke imale u cilju osnaživanja njihovih kompetencija. Od ispitanika se tražilo da se izjasne da li su obuke imale efekata na njihov lični i profesionalni razvoj, ali ne i u kojoj meri.

Obukama je prethodio detaljan snimak stanja u organizaciji, istraživanje o zadovoljstvu zaposlenih i njihovim obrazovnim potrebama, definisanje ciljeva i ishoda obuka, GAP analiza, strategija razvoja organizacije i akcioni plan za njenu realizaciju. Na osnovu utvrđenog stanja, odabrane su obrazovne teme relevantne za potrebe organizacije i metoda rada.

\title{
3. REZULTATI EVALUACIJE
}

Kako bismo imali jasniji pregled rezultata evaluacije, na ovom mestu ćemo prvo prikazati obuhvaćenost ispitanika istraživanjem:

\footnotetext{
1 o1. i 14. novembra i 05. decembra 2019. realizovana su grupne obuka za za menadžment, a za zaposlene 15., 16., 22., 23., 28., 29. januara i 12., 14. i 19. februara 2020.,
} 


\begin{abstract}
Zbornik IKSI, 2-3/2021 - H. Glomazić
„Evaluacija efektivnosti grupnih i individualnih obuka u organizaciji u cilju unapređivanja

kompetencija zaposlenih", (str. 9-20)
\end{abstract}

Tabela br. 1: Obuhvaćenost ispitanika istraživanjem

\begin{tabular}{l|c|c} 
Opis & Broj zaposlenih & Procenat \% \\
\hline Broj zaposlenih u Društvu & 65 & 100 \\
\hline Broj ispitanih & 64 & 98
\end{tabular}

U tabeli broj 1, dat je prikaz obuhvaćenosti ispitanika istraživanjem. Kao što se može videti iz tabele, u organizaciji je 65 zaposlenih radnika. Od ukupnog broja zaposlenih, ispitivanjem je obuhvaćeno njih $98 \%$ koji rade po ugovorima na neodređeno i određeno vreme i ugovorima o privremenim i povremenim poslovima, a radno su angažovani u tri poslovne zgrade u okviru poslovnog kompleksa. S obzirom na to da je evaluacija efektivnosti obuka deo šireg projekta na kome se radi nekoliko prethodnih godina, istraživanjem su obuhvaćeni svi zaposleni (budući da su odgovarali na set pitanja o organizacionim promenama) iako neki nisu bili radno angažovani u periodu realizacije obuka. Iz tog razloga je prvo prikazana obuhvaćenost ispitanika, a zatim broj onih koji su se izjasnili o efektivnosti obuka.

U tabeli broj 2 dat je pregled broja ispitanika koji su se izjasnili o efektivnosti obuka:

Tabela br. 2: Ispitanici koji su se izjasnili o efektivnosti obuka

\begin{tabular}{l|c|c}
\multicolumn{1}{c|}{ Opis } & Broj zaposlenih & Procenat \% \\
\hline $\begin{array}{l}\text { Ispitanici koji su se izjasnili } \\
\text { o efektivnosti obuka }\end{array}$ & 56 & 87 \\
\hline $\begin{array}{l}\text { Ispitanici koji se nisu izjasnisli ili nisu } \\
\text { prisustvovali obukama }\end{array}$ & 8 & 13
\end{tabular}

Od ispitivanjem obuhvaćenih $98 \%$ zaposlenih, njih $13 \%$ se nije izjasnilo o efektivnosti obuka, jer nije prisustvovalo ni jednoj vrsti obuke, budući da su zasnovali radni odnos nakon završenog programa grupnih obuka i/ili nisu koristili mogućnost individualnih obuka. Ostalih $87 \%$ se izjasnilo o efektivnosti obuka. Oni su koristili jednu i/ili obe forme obuke.

U nastavku pregleda rezultata evaluacije, daćemo prikaz strukture zaposlenih:

Tabela br. 3: Pol ispitanika

\begin{tabular}{l|c|c} 
Pol ispitanika & Broj zaposlenih & Procenat \% \\
\hline Muški & 25 & 45 \\
\hline Ženski & 31 & 55
\end{tabular}

Od ukupnog broja ispitanika, $55 \%$ je ženskog, a $45 \%$ muškog pola, što govori o ujednačenoj distribuciji ispitanika u odnosu na pol. 


\begin{abstract}
Zbornik IKSI, 2-3/2021 - H. Glomazić
„Evaluacija efektivnosti grupnih $\mathrm{i}$ individualnih obuka u organizaciji u cilju unapređivanja kompetencija zaposlenih", (str. 9-20)
\end{abstract}

Tabela br. 4 - Struktura zaposlenih prema godinama starosti

\begin{tabular}{l|c|c} 
Opseg godina starosti & Broj zaposlenih & Procenat \% \\
\hline Od 25 do 35 godina & 6 & 11 \\
\hline Od 36 do 45 godina & 19 & 34 \\
\hline Od 46 do 55 godina & 17 & 30 \\
\hline Od 56 do 65 godina & 13 & 23 \\
\hline Preko 65 godina & 1 & 2
\end{tabular}

Podaci iz tabele broj 4 govore da je u kategoriji od 25 do 35 godina starosti $11 \%$ ispitanika; u kategoriji od 36 do 45 godina starosti je $34 \%$; u kategoriji od 46 do 55 godina starosti je $30 \%$, od 56 do 65 godina starosti je $23 \%$, dok je u kategoriji preko 66 godina starosti $2 \%$ ispitanika. Najveći broj zaposlenih je u kategoriji od 36 do 55 godina starosti, zbirno čak 64\%. To sugeriše na pretpostavku (koju bi trebalo istraživanjem proveriti) da je s obzirom na rastući trend promena koje se događaju u svetu rada (digitalizacija poslovanja, elektronsko poslovanje, korišcenje naprednih softvera u poslovanju, onlajn sastanci, rad na daljinu i slično), ovoj kategoriji potrebna stručna podrška kako bi se unapredile njihove kompetencije i poslovne performanse.

Tabela br. 5: Struktura zaposlenih prema godinama radnog staža

\begin{tabular}{l|c|c} 
Opseg godina radnog staža & Broj zaposlenih & Procenat \% \\
\hline Od o do 10 godina & 11 & 20 \\
\hline Od 10 do 20 godina & 14 & 25 \\
\hline Od 20 do 30 godina & 20 & 36 \\
\hline Od 30 do 40 godina & 9 & 16 \\
\hline Preko 40 godina & 2 & 3
\end{tabular}

Iz tabele broj 5 možemo videti da je struktura zaposlenih u pogledu godina radnog staža sledeća: u kategoriji od o do 10 godina radnog staža je $20 \%$ ispitanika u kategoriji od 10 do 20 godina radnog staža je $25 \%$, u kategoriji od 20 do 30 godina radnog staža je $36 \%$, u kategoriji od 30 do 40 godina radnog staža je16 \%, dok je u kategoriji preko 40 godina radnog staža $3 \%$ ispitanika. Podaci o godinama radnog staža mnogo ne odstupaju od podataka o godinama starosti, tako da je najveći procent zaposlenih u kategoriji od 10 do 30 godina radnog staža, njih 61\%. Dakle, u odnosu na karakteristike uzorka, moće se reći da se radi o sličnoj kategoriji zaposlenih kojima je potrebno unapređivanje kompetencija putem stručnog usavršavanja. 


\begin{abstract}
Zbornik IKSI, 2-3/2021 - H. Glomazić
„Evaluacija efektivnosti grupnih $\mathrm{i}$ individualnih obuka u organizaciji u cilju unapređivanja

kompetencija zaposlenih", (str. 9-20)
\end{abstract}

Tabela br. 6: Struktura zaposlenih prema nivou obrazovanja

\begin{tabular}{l|c|c}
\multicolumn{1}{c|}{ Nivo obrazovanja } & Broj zaposlenih & Procenat \% \\
\hline Osnovna škola & 3 & 5 \\
\hline Srednja strukovna škola & 14 & 25 \\
\hline Srednja škola & 12 & 22 \\
\hline Viša škola & 3 & 5 \\
\hline Fakultet & 22 & 39 \\
\hline Master & 2 & 4
\end{tabular}

U tabeli broj 6 prikazana je struktura zaposlenih u odnosu na nivo obrazovanja, pa je tako prema ovoj varijabli distribucija ispitanika sledeća: ispitanika sa osnovnom školom je $5 \%$, sa srednje stručnim obrazovanjem $25 \%$, sa srednjom školom $22 \%$, sa višom strukovnom $5 \%$, sa završenim fakultetom $39 \%$, dok je sa master diplomom njih $4 \%$.

Zaposleni sa osnovnom i srednjom stručnom spremom su u najvećem broju slučajeva radno angažovani na pozicijama kvalifikovanih radnika. U projektu se insistiralo da i oni budu ravnopravno uključeni u obrazovne aktivnosti kako bi se na taj način stekao osećaj pripadnosti kolektivu, razbio stereotip o nepotrebnosti usavršavanja radnika sa nižim nivoom obrazovanja i doprinelo njihovom aktivnom uključivanju u program usavršavanja.

Moramo da zapazimo da se iz ove kategorije zaposlenih mali broj njih odazvao na individualni program obuke i savetovanja. Naša pretpostavka je da ispitanici sa nižim obrazovanjem nisu u dovoljnoj meri bili osnaženi da se samostalno prijave za program individualnih obuka iako su u razgovoru o efektivnosti grupnih obuka imali veoma zanimljiva i korisna zapažanja. Kao ilustraciju navešćemo neka njihova zapažanja:

Ispitanik 1: „Bio sam na svim seminarima. Koristim sve i zaista razmišljam o onome što sam čuo na seminarima. Mi smo dosta toga promenili i u komunikaciji i u ponašanju. To je imalo efekta na rad cele organizacije“.

Ispitanik 2: „Od kada se koristi ovaj program rada mnogo su bolji međuljudski odnosi iako je potrebno još rada na tome“.

Ispitanik 3: „Tada nisam bio siguran šta će nam to, ali tek sada vidim da smo rešili dosta problema jer je od tada počelo da se nešto menja.“

Ispitanik 4: „Naravno da je imalo efekta, za mene i lično i za posao. Gde bih ja to mogao inače da čujem.“ 


\begin{abstract}
Zbornik IKSI, 2-3/2021 - H. Glomazić
„Evaluacija efektivnosti grupnih i individualnih obuka u organizaciji u cilju unapređivanja kompetencija zaposlenih", (str. 9-20)
\end{abstract}

Tabela br. 7: Struktura ispitanika prema participaciji u vrsti obuke

\begin{tabular}{l|c|c}
\multicolumn{1}{c|}{ Vrsta obuke } & Broj zaposlenih & Procenat \% \\
\hline Grupne obuke & 51 & 91 \\
\hline Individualne obuke & 25 & 45 \\
\hline Grupne i individualne obuke & 20 & 36
\end{tabular}

Od ukupno 56 zaposlenih koji su participirali u programu obuka, $91 \%$ je participiralo u grupnim obukama, 45\% u programu individualnih obuka, dok je njih $36 \%$ participiralo u obe vrste obuke. Participacija u programu individualnih obuka je znatno niža nego u grupnim, što je rezultat kombinacije različitih faktora organizacione i personalne prirode, a i početnog nepoverenja zaposlenih prema samom programu.

Neki od ispitanika su to naveli u svojim komentarima:

Ispitanik 5: „U početku se nije blagonaklono gledalo na ovu vrstu obuke, ali se vremenom to promenilo. Meni su obuke i jedne i druge veoma koristile i na ličnom i na poslovnom planu. Primenjujem ono što smo radili, naročito u donošenju odluka, delegiranju zadataka, postavljanju granica. Od kada sam počela da primenjujem ono što smo naučili u vezi pisane komunikacije, poštovanju rokova mnogo je jednostavnije, nema onakvih konflikata. Ali, ima tu još da se radi. “"

Tabela br.8: Evaluacija efektivnosti grupnih obuka

\begin{tabular}{l|c|c} 
Nivo efikasnosti obuka & Broj zaposlenih & Procenat \% \\
\hline Efektivne su & 45 & 88 \\
\hline Nisu efektivne & 3 & 6 \\
\hline Delimično su efektivne & 3 & 6
\end{tabular}

Kako se može zaključiti iz tabele broj 8, zaposleni su u visokom procentu ocenili efektivnost grupnih obuka. Od 51 zaposlenih koji su participirali u programu grupnih obuka, njih $88 \%$ je procenilo da su obuke bile efektivne. Takođe, $6 \%$ zaposlenih je ocenilo da su obuke bile delimično efektivne, a $6 \%$ njih da nisu bile efektivne.

Neki smatraju da je potrebno ponoviti grupne obuke nakon izvesnog vremena, jer bi se tako održavalo i proveravalo naučeno.

Ispitanik 6: „Vremenom treba ponavljati grupni rad u cilju usavršavanja veština zaposlenih, osvežavanja i održavanja znaja koja smo dobili“.

Rezultat efektivnosti grupnih obuka je izraženo visok, što nisu bila očekivanja istraživača. 


$$
\begin{gathered}
\text { Zbornik IKSI, 2-3/2O21 - H. Glomazić } \\
\text { „Evaluacija efektivnosti grupnih i individualnih obuka u organizaciji u cilju unapređivanja } \\
\text { kompetencija zaposlenih", (str. 9-20) }
\end{gathered}
$$

Tabela br. 9: Evaluacija efektivnosti individualnih obuka

\begin{tabular}{l|c|c} 
Nivo efikasnosti obuka & Boj zaposlenih & Procenat \% \\
\hline Efektivne su & 24 & $96 \%$ \\
\hline Nisu efektivne & 0 & 0 \\
\hline Delimično su efektivne & 1 & $4 \%$
\end{tabular}

U tabeli broj 9 su izneti podaci o efektivnosti individualnih obuka iz čega možemo videti da su ispitanici procenili da su i one, kao i grupne obuke, visokoefektivne. Od ukupnog broja ispitanih, njih 96\% procenjuje da su individualne obuke efektivne, dok $4 \%$ procenjuje da imaju delimičnu efektivnost. Niko od ispitanika nije negativno procenio efektivnost individualnih obuka. Douše, treba dodati da su u najvećem procentu visokoobrazovani zaposleni koristili individualna savetovanja, njih $75 \%$ (viša škola, fakultet i master).

Individualni program obuke je, kao što smo rekli, usmeren i na prevenciju stresa na radu i povećanje otpornosti na stres, kao i na upravljanje konfliktima. U tom smislu, individualni program obuke, koje je imalo formu savetovanja, je bio izraženo efektivan.

Ispitanik 7: „Ovo je pravi primer brige o ljudskim resursima. Bila sam na svim seminarima i grupne obuke ocenjujem veoma visokom ocenom, ali bih prednost dala individualnim obukama ili savetovanjima, kako ih mi zovemo, jer su mi značajno pomogli u napredovanju u poslu“.

Ispitanik 8: „Imao sam maksimalnu podršku koja mi je pružena u individualnim savetovanjima kada mi je bilo najteže, što mi je pomoglo da nastavim sa poslom.“

Ispitanik 9: „I grupni i individualni rad mi je prijao i mogu da kažem da je bilo veoma značajno za službu, i na poslovnom i privatnom planu. Ljudi su mogli da se osete prihvaćenim, da prevaziđu poslovne krize, a da se to ne odrazi na poslovni proces i to je bilo veoma značajno. Poslovni rezultati su vidno bolji, što je posledica ukupnog rada menadžmenta, ljudi su više motivisani za rad. Mislim da se zaposleni osećaju dobro gde rade, da ne rade pod pritiskom i stresom i da ako postoji, to sada svedeno na minimum“.

Ispitanik 10. „Zahvalna sam što mi je omogućena podrška i pomoć u rešavanju problema koji su bili vezani za posao, a mogli su da se negativno odraze na moje zdravlje. Tu mislim na individualno savetovanje gde sam uspostavila odnos poverenja. Pohvaljujem savetovanje kao opciju, jer mi je ovaj benefit lično najpotrebniji i najvažniji“.

Iz podataka dobijenih istraživanjem može se zaključiti da su ispitanici bez obzira na socio-demografske karakteristike obuke evaluirali kao visokoefektivne. 


\author{
Zbornik IKSI, 2-3/2021 - H. Glomazić \\ „Evaluacija efektivnosti grupnih i individualnih obuka u organizaciji u cilju unapređivanja \\ kompetencija zaposlenih", (str. 9-20)
}

\title{
DISKUSIJA
}

Rezultati su pokazali da ispitanici veoma pozitivno procenjuju efektivnost kako grupnih, tako i individualnih obuka, uprkos podacima iz literature koji sugerišu na zaključak da su efekti obuka teško merljivi i da je njihova učinkovitost upitna. Čini se da su u našem slučaju za ovako visoko postignuće zaslužne ne samo obrazovne intervencije, već ceo kontekst u kome su se one odvijale.

Naime, kao što smo prethodno naglasili obuke su bile deo šireg projekta koji je imao za cilj promenu organizacione kulture, povećanje zadovoljstva zaposlenih, a time i njihove produktivnosti. To znači da su u organizaciji preduzete brojne aktivnosti kako bi se taj cilj postigao. Takođe, činjenica je da je sve vreme trajanja projekta praćena implementacija mera i kontrolisano njihovo sprovođenje. Početno nepoverenje i skepsa u mogućnost organizacionih promena vremenom se menjalo i to zahvaljujući postupnom radu, sprovođenju strategije razvoja i komunikacije i ispunjavanju akcionog plana u kome su definisani ciljevi i rokovi za njihovu realizaciju; konkretnim i vidljivim promenama do kojih je došlo nakon obrazovnih intervencija u obliku istraživanja zadovoljstva zaposlenih, obuka, savetovanja, grupnih i individualnih konsultativnih sastanaka, ocenjivanja radnog učinka zaposlenih. U tom smislu pre smo spremni da zaključimo da je visoko ocenjena efektivnost obuka više proizvod procene celokupnog rada na organizacionim promenama nego isključivo same obrazovne aktivnosti.

U literaturi postoji više modela evaluacije efektivnosti obuka, ali se istraživači slažu da nije lako izmeriti obrazovni učinak obuke u organizaciji, naročito ne odmah nakon njenog završetka. Glavni aspekt Kirkpatrikovog modela evaluacije (Mihailova et al., 2018) je da se ona ne završava u jednom koraku, već da je to složen proces kome je cilj ne samo da utvrdi ishod učenja, već i održivost postavljenih ciljeva. Njegov model sadrži četiri nivoa i to: reakciju, učenje, ponašanje i rezultate (Mihailova et al., 2018).

Naš model evaluacije kroz ceo projekat sadržao je sve bitne elemente Kirkpatrikovog modela, budući da je projekat trajao od decembra 2017. do novembra 2021. godine. Ali smo u ovom radu predstavili evaluaciju „drugog talasa“ (Mihailova et al., 2018), ponovljenu nakon svih prethodnih evaluacija koje su bile urađene neposredno nakon izvedene obuke upravo da bi se mogla proceniti održivost postavljenih ciljeva.

S druge strane, objašnje za ovako visok procent efektivnosti može se tražiti u samoj metodologiji rada istraživača, odnosno u odabiru istraživačke tehnike. Upotreba strukturiranog intervjua i direktnog razgovora istraživača koji je istovremeno bio i jedan od realizatora grupne obuke i jedini realizator individualnih obuka, mogla je uticati na ispitanike da se izjasne izrazito pozitivno. $\mathrm{U}$ tom smislu, rezultate treba uzeti sa izvesnom rezervom. 


\author{
Zbornik IKSI, 2-3/2021 - H. Glomazić \\ „Evaluacija efektivnosti grupnih i individualnih obuka u organizaciji u cilju unapređivanja \\ kompetencija zaposlenih", (str. 9-20)
}

\title{
ZAKLJUČAK
}

Stručno usavršavanje i preduzimanje obrazovnih aktivnosti i intervencija $u$ organizaciji postaje dominantan oblik rada, naročito u organizacijama koje su uspešne. Bez orijentacije organizacije da se generalno unapredi organizaciona kultura i kontinuirano planira i prati unapređivanje kompetencija zaposlenih, verujemo da ni efektivnost obrazovnih intervencija ne bi bila veoma uspešna. Verujemo da je najbolji način rada stvaranje sinergije između internih mera koje preduzima organizacija i kontinuiranog sprovođenja obrazovnih aktivnosti koje se utvrđuju unutrašnjim aktima. U nekim istraživanjima je potvrđeno da multimodalni pristupi koji koriste više različitih aktivnosti daju bolje rezultate (Glomazić, 2020).

U literaturi koja tretira pitanja razvoja ljudskih resursa navodi se značaj orijentacije organizacije na razvoj organizacione kulture, pa se kaže da se uspešne kompanije razlikuju od neuspešnih jer njihovu „organizacionu kulturu karakterišu norme i standardi koji podstiču organizaciono ponašanje usmereno na kontinuirani rast i razvoj, a ne na bezbednost i prosek. Planiranje razvoja je posebno važno za one kompanije koje svoju snagu grade na znanju i veštinama zaposlenih“ (Slavković \& Slavković, 2019, str. 117).

\section{LITERATURA:}

(1) Acton, T. \& Golden, W. (2003). Training the Knowledge Worker: A Descriptive Study of Training Practices in Irish Software Companies. Journal of European Industrial Training, 27(2-4), 137-146.

http://dx.doi.org/10.1108/03090590310468958

(2) Chih, J., Lee, H. \& Liu, C. (2008). Relationship between Trainee Attitudes and Dimensions of Training Satisfaction: An Empirical Study with Training Institute Employees. International Journal of Management, 25(3), 756-765.

(3) European Commission. (2007). Toward common principles of Flexicurity: More and better jobs through flexibility and security. Luxemburg: Office for Official publications of The European Comunities.

(4) European Union. (2006). Recommendation 2006/962/EC of the European Parliament and of the Council of 18 December 2006 on Key Competences for Lifelong Learning.

(5) Glomazić, H., Ljumović, I. \& Jakšić, K. (2020). Uloga formalnog obrazovanja za preduzetništvo u kreiranju nove generacije preduzetnika. Andragoške studije, 127146. http://dx.doi.org/10.5937/AndStud2001127G

(6) Glomazić, H. (2020). Organizacioni pristup prevenciji stresa na radu i očuvanju mentalnog zdravlja zaposlenih. Zbornik Instituta za kriminološka i sociološka istraživanja, 39(2/3), 45-58. http://dx.doi.org/10.47152/ziksi2020233

(7) Goldstein, I. L. \& Ford, J. K. (2002). Training in Organizations. Belmont, CA: Wadsworth, $4^{\text {th }}$ edition.

(8) Kraiger, K. (2017). Training from an organizational psychology perspective. In: Oxford Research Encyclopedia of Psychology.

https://doi.org/10.1093/acrefore/9780190236557.013.33 


\author{
Zbornik IKSI, 2-3/2021 - H. Glomazić \\ „Evaluacija efektivnosti grupnih i individualnih obuka u organizaciji u cilju unapređivanja \\ kompetencija zaposlenih", (str. 9-20)
}

(9) Mihailova, Z., Mandic, D., Valentinc, S., Schiffer, J., Happe, C. \& Erdmann, K. (2018). Upravljanje ciklusom obuke. IPA 2014 Tvining Projekat „Dalja podrška reformi pravnog obrazovanja“. Dostupno na http://jus.igjk.rks-

gov.net/777/3/20180710\%20Handbook\%20on_Management\%20of\%20the\%20Tra ining\%20Cycle_draft\%20SERB.pdf pristupljeno 12.11.2021.

(10) Pejatović, A. \& Pekeč, K. (2011). Evaluacija u sistemu kvaliteta stručnih obuka za odrasle. U: N. Kačavenda Radić, D. Pavlović Breneselović, \& R. Antonijević (ur), Kvalitet u obrazovanju (str. 173-187). Beograd: Institut za pedagogiju i andragogiju Filozofskog fakulteta Univerziteta u Beogradu.

(11) Slavković, A., \& Slavković, V. (2019). The importance of training in contemporary organizations. Hotel and Tourism Management, 7(2), 115-125.

http://dx.doi.org/10.5937/menhottur1902115S

(12) Stanišić Vještica, O.Ž. (2016). Uticaj obuke i obrazovanja na performanse organizacije i zadovoljstvo zaposlenih (Doktorska disertacija). Univerzitet Union Beogradska bankarska akademija - Fakultet za bankarstvo, osiguranje i finansije. Dostupno https://docplayer.net/94377448-Uticaj-obuke-i-obrazovanja-naperformanse-organizacije-i-zadovoljstvo-zaposlenih.html pristupljeno 16.11.2021

(13) Nacionalni okvir kvalifikacija u Srbiji (2017). Dostupno na: http://noks.mpn.gov.rs/sr_lat/pojmovnik/ pristupljeno 30.11.2021.

(14) Uredba o određivanju kompetencija za rad državnih službenika, Službeni glasnik RS, 4/2019 https://www.pravno-informacionisistem.rs/SlGlasnikPortal/eli/rep/sgrs/vlada/uredba/2019/4/1

(15) Zakon o radu "Sl. glasnik RS", br. 24/2005, 61/2005, 54/2009, 32/2013, 75/2014, 13/2017 - odluka US, 113/2017 i 95/2018.

\title{
EVALUATION OF THE EFFECTIVENESS OF GROUP AND INDIVIDUAL TRAINING IN THE ORGANIZATION TO IMPROVE THE COMPETENCIES OF EMPLOYEES
}

The subject of this paper is the evaluation of the effectiveness of group and individual training in the organization. This paper aims to answer the question of whether the conducted group and individual training were effective in terms of improving the competencies of employees. The method used is a structured interview. The results showed that the respondents estimated that both group and individual training were highly effective, both personally and professionally. However, we believe that such a highly rated effectiveness of training is more a product of the synergy of the overall work of the organization on organizational change and the educational interventions undertaken than exclusively the educational activities themselves.

KEYWORDS: organization / competencies / trainings / training effectiveness / human resources 